\title{
Influences of Waste Concrete Powder on the Strength Development and Hydration Products of Mortar Containing Fly Ash
}

\author{
Huashan YANG, Yujun CHE* \\ School of Materials and Architecture Engineering, Guizhou Normal University, Guiyang 550025, China \\ crossref http://dx.doi.org/10.5755/j02.ms.25591
}

Received 30 March 2020; accepted 21 July 2020

\begin{abstract}
During recycling waste concrete, a large amount of waste concrete powder (WCP) is generated. However, efficient utilization of WCP remains an unresolved issue. This paper investigates the influences of WCP on the properties and hydration products of cement mortar containing fly ash (FA). This study used two different types of WCPs. One was made from an ordinary Portland cement mortar, and the other was derived from a Portland cement mortar. WCP replaced $10 \%, 20 \%$, and $30 \%$ of FA. The water requirement, setting time, flow index, strength, hydration products, and microstructure of FA mortar incorporating WCP were investigated. Test results indicate that the WCP has no significant influence on the performances and hydration products of FA mortar. By adequately combining WCP and FA, the FA mortar with required performances could be reached.

Keywords: Fly ash; Waste concrete powder; mortar; hydration products; strength
\end{abstract}

\section{INTRODUCTION}

It is reported that waste concrete is the primary component of total solid waste produced in the world, which creates a severe ecological and environmental problem [1]. Recently, recycling of waste concrete to ensure environmental sustainability has become a global issue [2-5]. Using this waste as a recycled concrete aggregate (RCA) to substitute natural aggregate is of great significance for environmental protection and sustainable development [6-11]. However, these studies mainly focus on the coarse RCA and fine RCA. Only limited literature has reported the fresh and hardened performances of concrete incorporating WCP, which is a by-product of the process of producing RCA [12].

WCP is a fine powder fraction from the demolition waste of old concrete. It takes about $10 \sim 20 \%$ of the old concrete [13]. The utilization of WCP in cementitious materials is beneficial and necessary for environmental protection [14-17]. Florea et al. reported the possibility of replacing partial cement in concrete with WCP [18]. They found that WCP to be a useful supplementary cementitious material (SCM), especially when using blended cement. Kim et al. [14], also found that WCP can replace partial ordinary Portland cement in producing self-consolidating concrete. Liu et al. studied WCP recovered by the dust collection system [19]. They found that WCP can be used as a supplementary cementitious material for concrete because of its pozzolanic activity. Prošek et al. suggest that WCP can be incorporated into cementitious materials containing FA or blast furnace slag in large amounts [20].

Fly ash, a solid waste produced by coal-fired power plants, is looked upon as an SCM in cement concrete [21]. The substitution of cement with FA not only reduces energy production but also reduces carbon dioxide emissions during cement production [22]. Besides, FA

\footnotetext{
* Corresponding author. Tel.: +86-851-86846935.

E-mail address: 201602003@gznu.edu.cn (Y. Che)
}

improves workability, mechanical strength, and durability of cement concrete, but reduces the heat of hydration of cement [23-27]. Nevertheless, the availability of FA is limited. There is an urgent need to use new supplementary cementitious materials, such as WCP to replace FA. Furthermore, considering the variety of WCP sources that would be available, an investigation of the influences of different WCP is required to evaluate these recycling materials.

This study focuses on the feasibility of producing FA mortar incorporating WCP. The influence of WCP on the water requirement, setting time, flow index, and strength development of FA mortar were measured. The microstructure and hydration products of the fly ash mortar with WCP were also investigated by X-ray diffraction (XRD), scanning electron microscopy (SEM), differential thermal gravity (DTG) and thermal gravimetric (TG) analyses.

\section{MATERIALS AND METHODS}

\subsection{Materials}

Portland cement ( $\mathrm{P} \cdot \mathrm{I}$ 42.5), FA, two kinds of WCPs (WCP-1 and WCP-2), and silica sand were used in this work. FA, WCP-1, and WCP-2 were selected as supplementary cementitious materials. The WCP-1 and WCP-2 were prepared by crushing and grinding the hardened Portland cement mortar and ordinary Portland cement mortar. The hardened cement mortar was produced at a water to cement ratio of 0.5 and cured in a moisture room for 28 days.

The particle size distribution (PSD) of the WCP-1, WCP-2, and FA were measured using a laser diffraction spectroscopy (Malvern Mastersizer model MS 2000). The PSD of WCP-1, WCP-2, and FA is shown in Fig. 1. The d (0.5) of WCP-1, WCP-2, and FA is $18.936 \mu \mathrm{m}, 20.403 \mu \mathrm{m}$, and $12.731 \mu \mathrm{m}$, respectively. It can be seen from this 
figure that WCP-1 and WCP-2 have larger particles than those of FA.

The chemical composition of WCP-1 and WCP-2 was determined by using an X-ray fluorescence analyzer (PANalytical B.V. model Axios advanced). Test results are listed in Table 1, where the chemical composition of FA is also shown for comparison. It can be seen from this table that the dominant elements of WCP are $\mathrm{Si}$ and $\mathrm{Ca}$, representing about $75 \%$ of the total mass, while the main elements of FA are $\mathrm{Si}$ and $\mathrm{Al}$, which count for about $80 \%$ of the total mass.

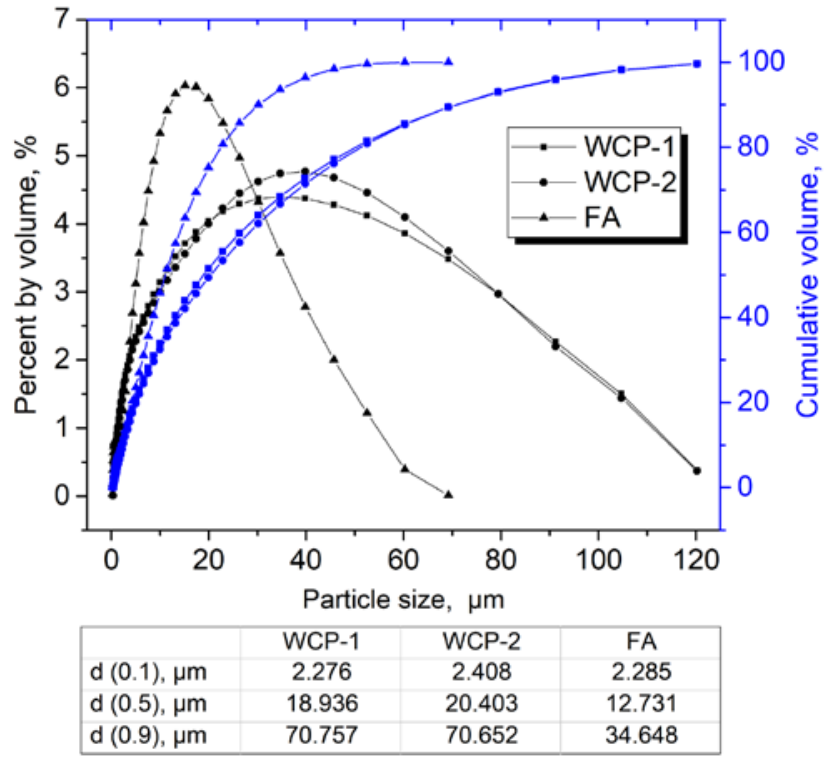

Fig. 1. PSD of WCP and FA by laser diffraction

Mineral constituents of WCP-1 and WCP-2 are analysed by XRD. As shown in Fig. 2, the main mineral constituents of WCP are calcium carbonate, $\mathrm{C}_{2} \mathrm{~S}$, calcium hydroxide $(\mathrm{CH})$, and quartz. The $\mathrm{C}_{2} \mathrm{~S}$ phase is unhydrated cement in the WCP specimens. The existence of unhydrated clinker may contribute to the strength development of cementitious materials. $\mathrm{CH}$ is typical in hardened cementitious materials, which indicate the hydration products. Thus, crushed aggregate particles, unhydrated clinker, and hydration products of cement constitute a significant component of WCP [28, 29].

Table 1. Chemical composition of WCP-1, WCP-2, and FA

\begin{tabular}{|l|l|l|l|}
\hline Chemical compound & WCP-1, \% & WCP-2, \% & FA, \% \\
\hline $\mathrm{SiO}_{2}$ & 29.74 & 29.68 & 45.29 \\
\hline $\mathrm{Al}_{2} \mathrm{O}_{3}$ & 3.17 & 3.03 & 22.13 \\
\hline $\mathrm{Fe}_{2} \mathrm{O}_{3}$ & 3.77 & 3.76 & 12.44 \\
\hline $\mathrm{CaO}$ & 47.22 & 46.26 & 3.37 \\
\hline $\mathrm{MgO}$ & 1.24 & 1.03 & 0.87 \\
\hline $\mathrm{Na}_{2} \mathrm{O}$ & - & 0.13 & 1.42 \\
\hline $\mathrm{K}_{2} \mathrm{O}$ & 0.54 & 0.68 & 1.71 \\
\hline $\mathrm{TiO}_{2}$ & 0.27 & 0.36 & 4.03 \\
\hline $\mathrm{MnO}$ & 0.17 & 0.13 & 0.13 \\
\hline $\mathrm{P}_{2} \mathrm{O}_{5}$ & - & 0.14 & 0.30 \\
\hline $\mathrm{SO}_{3}$ & 1.83 & 2.34 & 2.89 \\
\hline $\mathrm{CO}_{2}$ & 11.81 & 12.19 & 4.93 \\
\hline Others & 0.24 & 0.63 & 0.48 \\
\hline
\end{tabular}

Calcite in the XRD pattern comes from the carbonate generated during the grinding, which increases the LOI of
WCP. Quartz is derived from the crushed fine aggregates. Furthermore, it can be observed a weak amorphous phase about $30^{\circ}$ in this figure.

\subsection{Methods}

As shown in Table 2, an experiment was designed to investigate the influences of WCP content and type on the fresh state and hardened state performances of FA mortar. The ratio of FA to binder (the total of cement, FA, and WCP) at a constant value of 0.5 . Three different dosages of WCP-1 and WCP-2 were used in the mixes. The ratio of WCP to SCMs (the total weight of FA and WCP) is 0,10 , 20 , and 30 percent, respectively. All the rations are by weight. The flow index of FA mortar with WCP was tested according to ASTM C 1437. The mortar was prepared in prismatic molds $(40 \mathrm{~mm} \times 40 \mathrm{~mm} \times 160 \mathrm{~mm})$. The strength of specimens was measured after 7,28 , and 90 days of storage in a moisture room $\left(20 \pm 2{ }^{\circ} \mathrm{C}\right.$, $\mathrm{RH}>95 \%)$. Vicat tests were performed to investigate the influences of the WCP content on the standard consistency and the setting time of fresh FA pastes.

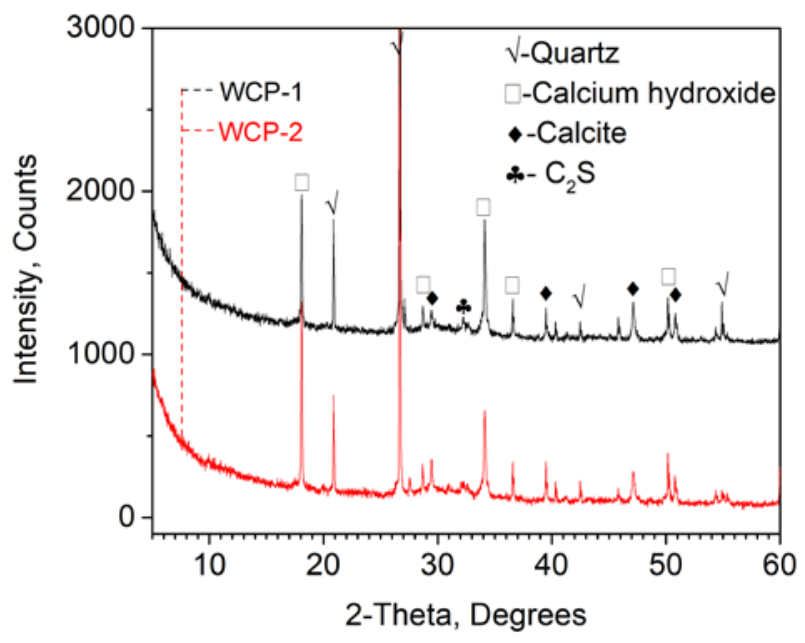

Fig. 2. XRD pattern of WCP-1 and WCP-2

Table 2. Mixture proportion of specimens

\begin{tabular}{|l|l|l|l|l|l|l|}
\hline Mixture & PC, g & FA, g & NCP-1, g & NCP-2, g & W, g & Sand, g \\
\hline M-0 & 225 & 225 & 0 & - & 225 & 1350 \\
\hline M-1 & 225 & 202.5 & 22.5 & - & 225 & 1350 \\
\hline M-2 & 225 & 180 & 45.0 & - & 225 & 1350 \\
\hline M-3 & 225 & 157.5 & 67.5 & - & 225 & 1350 \\
\hline M-4 & 225 & 202.5 & - & 22.5 & 225 & 1350 \\
\hline M-5 & 225 & 180 & - & 45.0 & 225 & 1350 \\
\hline M-6 & 225 & 157.5 & - & 67.5 & 225 & 1350 \\
\hline
\end{tabular}

A SEM (JSM-IT300) was used to study the morphology of WCP and FA particles. The morphology of hydration products and the microstructure of the specimens were also observed by SEM. XRD patterns were obtained a D8 Advance Diffractometer (Bruker-AXS). Operating conditions were set at a $40 \mathrm{kV}$ and $30 \mathrm{~mA}$ using a $\mathrm{Cu} \mathrm{Ka}$ $\mathrm{X}$-ray source. An analysis from $5^{\circ} \mathrm{C}$ to $60^{\circ} \mathrm{C}$ is carried out at a speed of $0.5^{\circ} \mathrm{C} / \mathrm{min}$. Both DTG and TG were performed on the specimens using a NETZSCH STA 449F3. The DTG depicts the thermal decompositions of phases in the specimens, while TG simultaneously determines the mass loss of a specimen with the 
temperature. The thermal analysis was performed in a nitrogen atmosphere at $20^{\circ} \mathrm{C}$ per minute from room temperature to $1000{ }^{\circ} \mathrm{C}$.

\section{RESULTS AND DISCUSSION}

\subsection{Morphology of WCP particle}

Fig. 3 describes the particle morphology of WCP-1, WCP-2, and FA. The particle morphology of WCP is very different from that of FA. WCP particles contain sharp edges and rough surfaces, which will increase the water requirement and thus decrease the flowability of cementitious materials. Furthermore, some cement paste from the original mortar is still attached to the surface of the stone powder particles. The enclosed paste is the main reason for the porous of WCP particles [14, 28, 30], which will increase the sorptivity coefficients and reduce the flowability of cementitious materials. It also can be observed that a lot of small particles are coated on the surface of WCP, which weakens the bond between the cement paste and WCP [31].
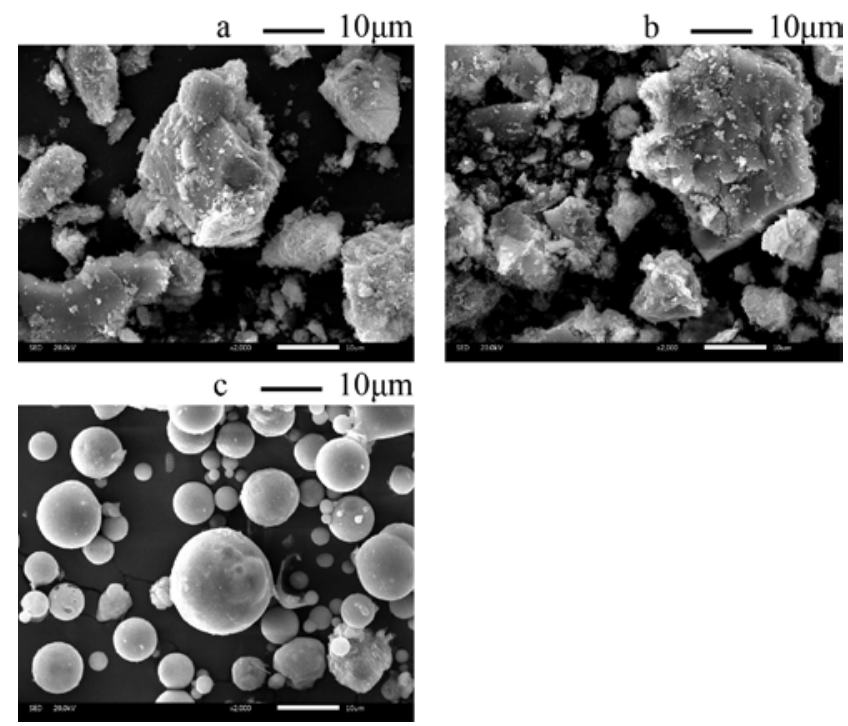

Fig. 3. SEM micrographs of WCP and FA: a - WCP-1; b-WCP2; $\mathrm{C}-\mathrm{FA}$

\subsection{Water requirement and setting time}

Fig. 4 shows the water requirement of cement paste containing FA and WCP, respectively. The water requirement of the specimen increases almost linearly with the increase of WCP content. For instance, replacing 10\%, $20 \%$, and $30 \%$ FA with WCP-1 increased the water requirement of the specimen $0.5 \%, 1.4 \%$, and $2.2 \%$, respectively. The results occurred because the surface structure of WCP particles is coarser than that of FA particles. Furthermore, the fine capillary pores in WCP particles increase the sorptivity, thus increase the water requirement of specimens. It is noted that replacing $10 \%$ FA with WCP had few adverse influences on the water requirement of specimens. Replacing $10 \%$ FA with WCP1 and WCP-2 only increased the water requirement of the specimen $0.5 \%$ and $0.7 \%$, respectively.

The initial and final setting time of specimens is shown in Fig. 5 a and b, respectively. As shown in Fig. 5 a that with the increase of WCP-1 or WCP-2, the initial setting time shows a decreasing tendency. It can be seen from Fig. 5 b, the final setting time decreased with increasing content of WCP. For example, replacing $10 \%$ FA with WCP-1 and WCP-2 decreased the final setting time of specimen $21.0 \%$ and $23.5 \%$, respectively. This is due to the accelerating effects of WCP on the hydration of cement [32]. The addition of WCP in specimens increases the nuclei for the crystal growth of hydration products, which accelerate the structure formation process.

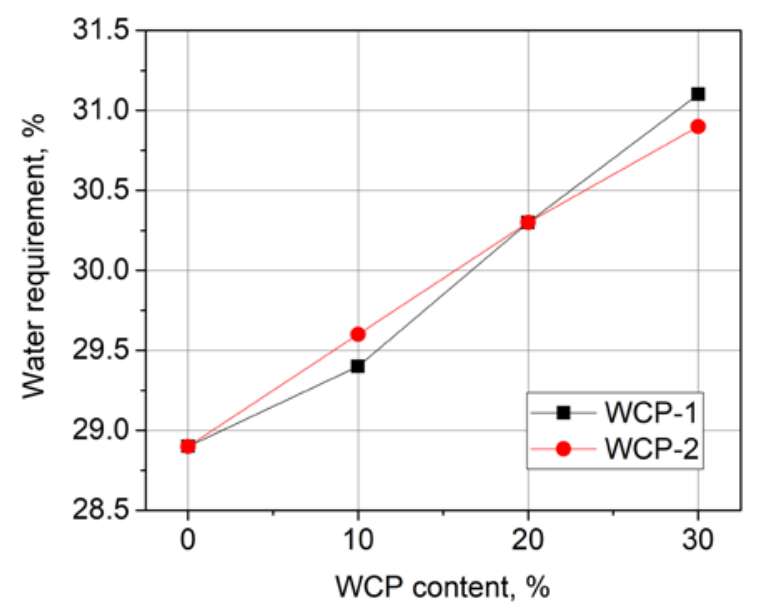

Fig. 4. Water requirement versus WCP content for specimens

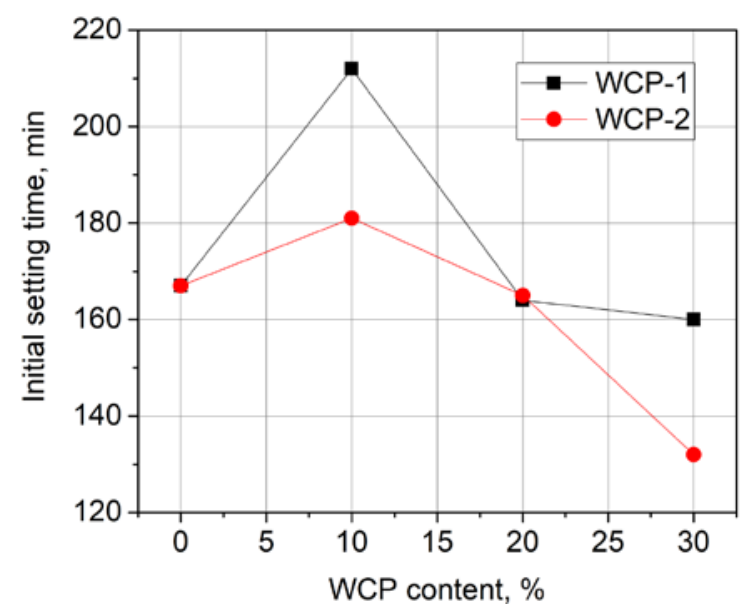

a

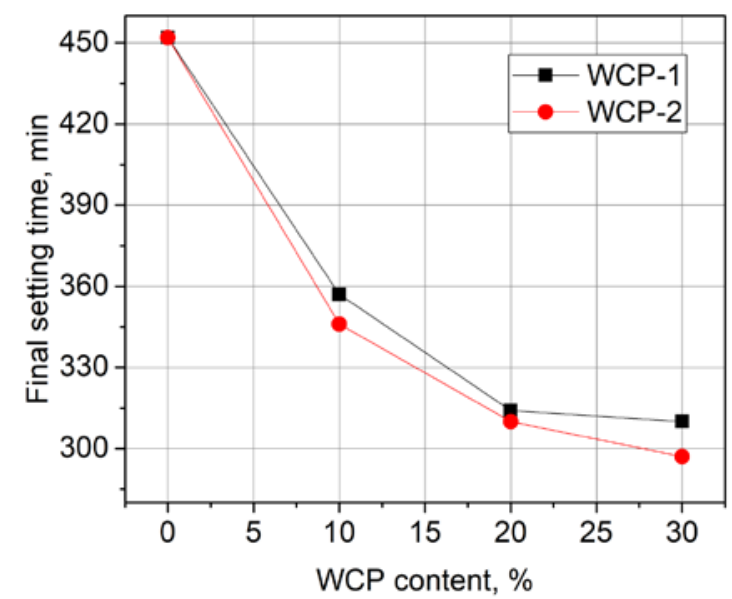

b

Fig. 5. Initial and final setting time versus WCP content for specimens: $a$-initial setting time; $b$ - final setting time 


\subsection{Flowability}

Fig. 6 shows the flow index of FA mortar containing WCP. Compared with the control specimen (FA mortar without WCP), replacing $10 \%$ FA with WCP has no significant adverse effect on the flowability of FA mortar.

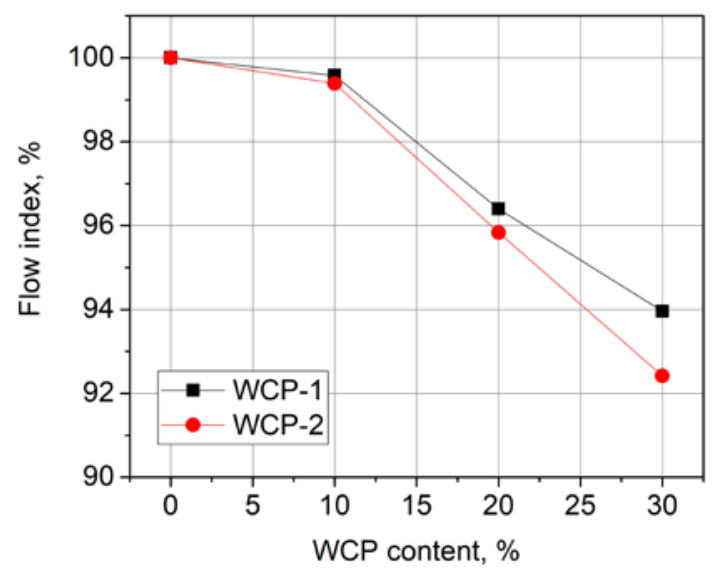

Fig. 6. Flow index versus WCP content for specimens

Replacing $10 \%$ FA with WCP-1 and WCP-2 decreased flow index, only $0.42 \%$ and $0.61 \%$, respectively. After that, the flow index of FA mortar rapidly reduced as the WCP content increased. For instance, replacing $20 \%$ and $30 \%$ FA with WCP-1 decreased flow index of $3.60 \%$ and $6.04 \%$, respectively. This is because the rough surface of WCP particles absorbs part of the water and consequently reduces the flowability of FA mortar [14]. Furthermore, as shown in Fig. 2, the roundness and sphericity of WCP particles are significantly lower than that of the fly ash particles, which also reduces the flow index of FA mortar containing WCP. It was thought that the spherical shape of particles might affect the rheology of cementitious materials [33].

\subsection{Strength development}

Fig. 7 shows the flexural and compressive strength of specimens containing WCP at 7, 28, and 90 days. It shows that the flexural and compressive strength of all specimens increases with curing ages. For instance, M-1 exhibited flexural and compressive strength of $9.1 \mathrm{MPa}$ and 49.9 $\mathrm{MPa}$ at 90 days, respectively, which is higher than that of at 7 and 28 days.

It can be seen from Fig. 1 that most particles of FA are finer than that of WCP. Hence, the microstructure of mortar containing FA may be more compact than that of mortar containing WCP. However, compared with control mortar (M-0), replacing $10 \%$ $20 \%$ FA with WCP did not adversely affect the strength of mortar at early-ages. Both the flexural and compressive strengths of $\mathrm{M}-1, \mathrm{M}-2$, M-4, and M-5 are equivalent to that of M-0 at 7 and 28 days, approximately. This may be due to the accelerating effects of WCP. It is reported that the C-S-H in WCP will act as a nucleus for further C-S-H formation, therefore accelerate the hydration reaction of clinker [34, 35]. After 28 days, both the flexural and compressive strengths of M-0 are slightly higher than those of M-1, M2, M-4, and M-5 due to the secondary reaction of FA. M-3 and M-4 exhibited lower flexural and compressive strengths than those of M-0 at all curing ages. The lower strength of FA mortar, incorporating $30 \%$ of WCP, can be attributed to the ITZ between the original aggregate and the hydrated cementitious materials [36]. The ITZ will significantly affect the strength of FA mortar containing WCP.

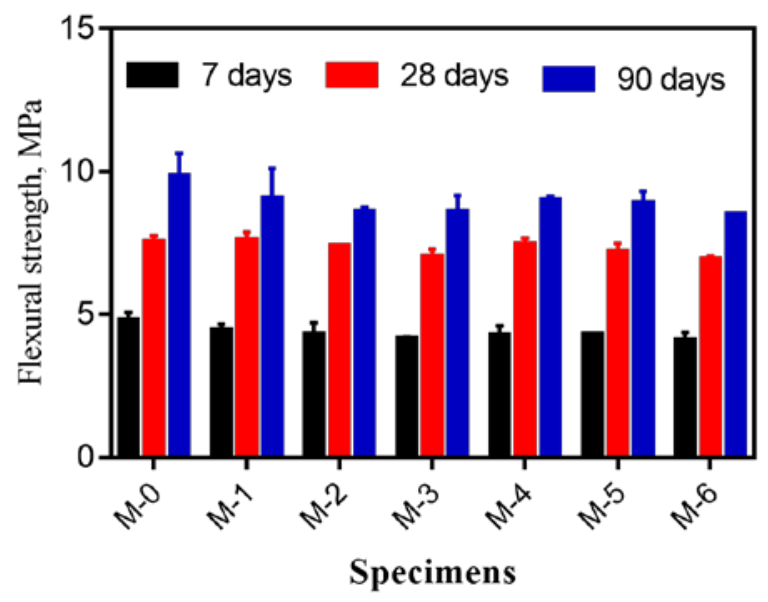

$\mathrm{a}$

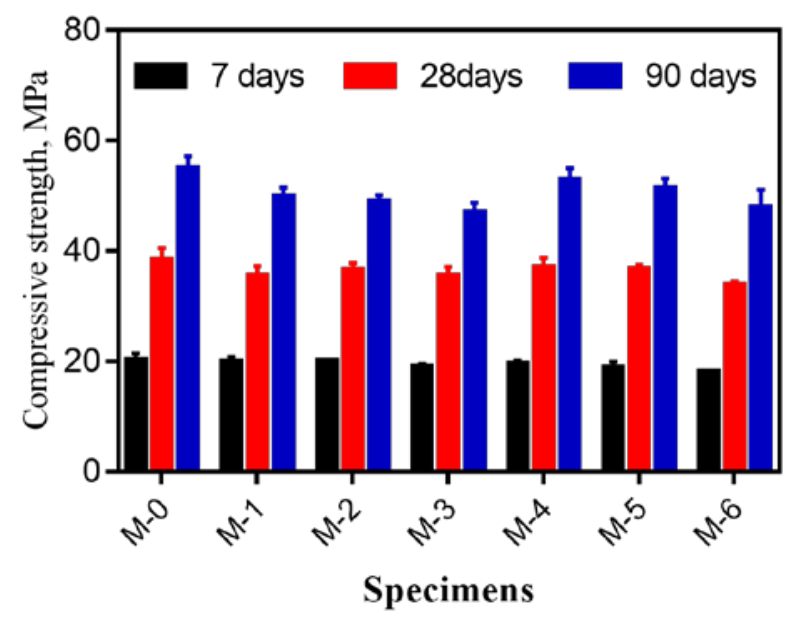

b

Fig. 7. Strength versus WCP content for specimens at 7, 28, and 90 days: $\mathrm{a}$ - flexural strength; $\mathrm{b}$ - compressive strength

Mortar incorporating a different type of WCP exhibited equivalent flexural and compressive strength at all ages, which indicates that the type of WCP has no significant effects on the strength of cement mortar.

\subsection{XRD analysis}

Fig. 8 shows the XRD analysis results for M-0 and M1 for 7 and 90 days, respectively. The diffraction peaks of quartz, calcite, and $\mathrm{CH}$ can be observed in the figure. Due to the presence of silica sand in the specimens, the mineral with the highest peak intensities is quartz. C-S-H cannot be identified in the XRD pattern because of its low crystallinity. Ettringite also cannot be identified on the XRD spectra. As shown in Fig. 8 a, the intensity of $\mathrm{CH}$ in the two specimens is almost the same. The same trend was also found in Fig. 8 b. The peak of $\mathrm{CH}$ was considered to be the primary indicator of the performances of specimens in this study. Therefore, the hydration products in FA 
mortar without WCP and FA mortar with $1 \%$ WCP do not show significant differences both at 7 and 90 days.
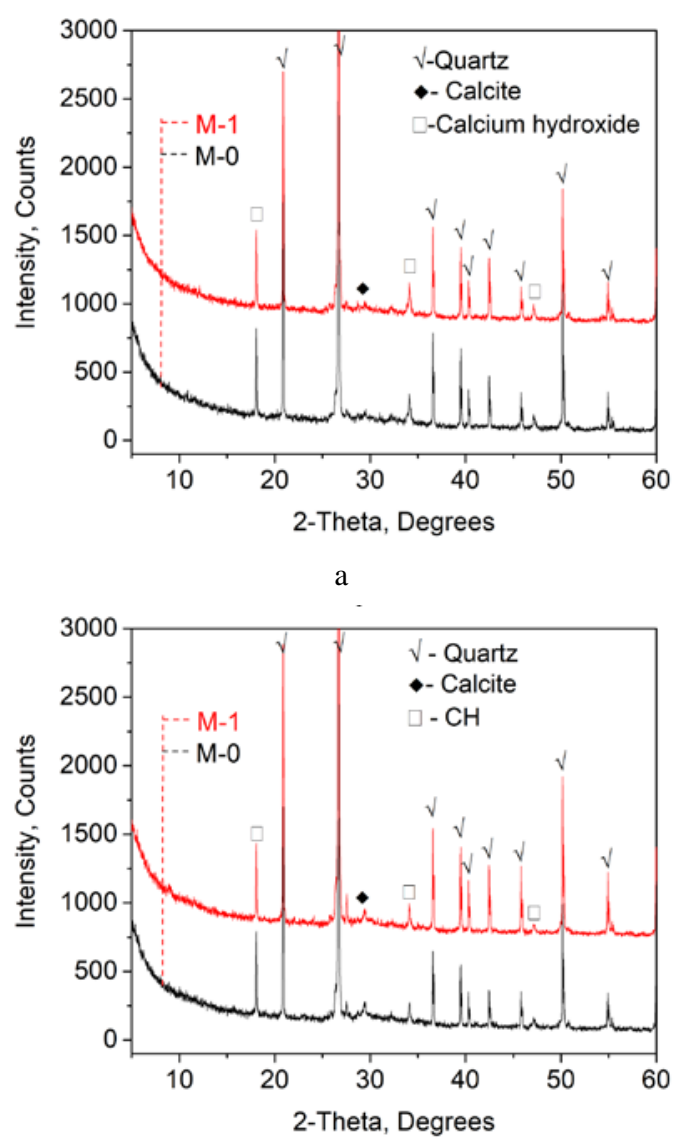

b

Fig. 8. XRD patterns of specimens: $a-7$ days; $b-90$ days

\subsection{DTG-TG analysis}

To quantitatively analyse the influences of WCP on the hydration products of specimens, $\mathrm{M}-0$, and $\mathrm{M}-1$ at 7 and 90 days were selected to conduct the DTG-TG analysis.

Fig. 9 gives the DTG and TG curves of M-0 and M-1 for 7 and 90 days, respectively. DTG curves show three main endothermic peaks.

Correspondingly, three rapid weight loss can be observed in the TG curves. Mass loss between $105^{\circ} \mathrm{C}$ and $400{ }^{\circ} \mathrm{C}$ represents the dehydration of C-S-H, and C-A-H et al., between $400{ }^{\circ} \mathrm{C}$ and $500{ }^{\circ} \mathrm{C}$ indicate the dehydration of $\mathrm{CH}$. De-carbonation of $\mathrm{CaCO}_{3}$ occurs at a temperature between $600{ }^{\circ} \mathrm{C}$ and $700{ }^{\circ} \mathrm{C}$. The $\mathrm{CH}$ content of specimens can be calculated according to Eq. 1 [37]:

$C H(\%)=W L_{\mathrm{CH}}(\%) \cdot M W_{\mathrm{CH}} / M W_{\mathrm{H}}$,

where $M W_{\mathrm{CH}}$ is the mass loss of $\mathrm{CH}, \% ; M W_{\mathrm{CH}}$ is the molecular weight of $\mathrm{CH}$; $M W_{\mathrm{H}}$ is the molecular weight of $\mathrm{H}_{2} \mathrm{O}$.

As expected, the $\mathrm{CH}$ content of the two specimens increases with increasing curing ages. M-0 and M-1 increased $\mathrm{CH}$ content of $57.6 \%$ and $41.9 \%$ at 90 days than that of at 7 days, respectively. This indicates an increase in the hydration degree of the cement. This phenomenon is consistent with the strength development shown in Fig. 7.

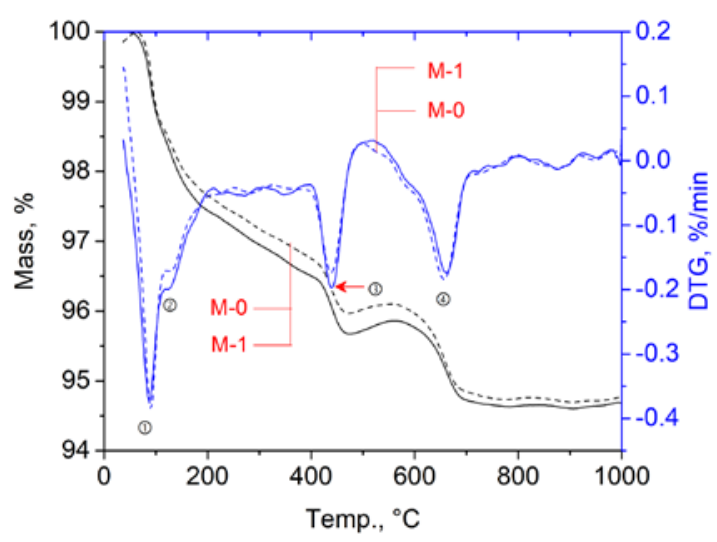

a

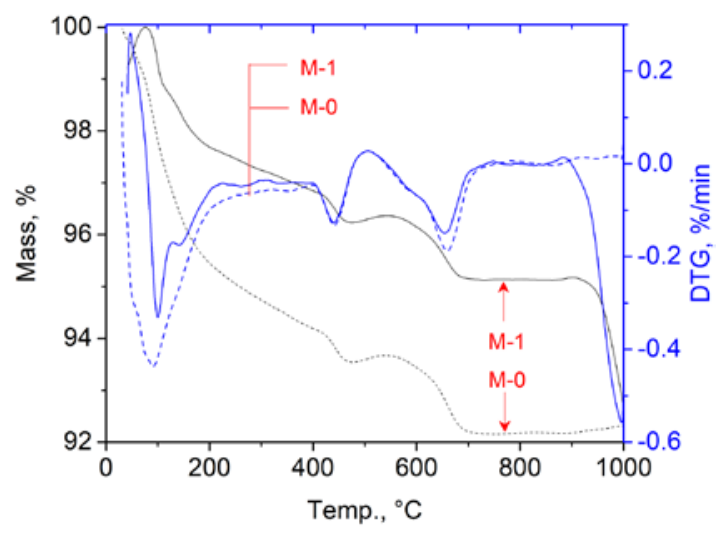

b

Fig. 9. DTG-TG curves of specimens: $a-7$ days; $b-90$ days

Besides, the $\mathrm{CH}$ content of M-0 is slightly higher than that of M-1 at 7 days, which indicates the accelerating effects of WCP on the hydration of clinker at early-ages. The accelerating effects can be attributed to the complicated surface structure of WCP particles, which increases the nuclei for the $\mathrm{CH}$ growth. However, the $\mathrm{CH}$ content of $\mathrm{M}-1$ is slightly lower than that of $\mathrm{M}-0$ at 90 days. The decrease in $\mathrm{CH}$ intensity can be attributed to the reaction of $\mathrm{CH}$ with $\mathrm{FA}$ at later ages.

\subsection{SEM imaging analysis}

To observe the microstructure of specimens, M-0 and M-1 were also investigated by SEM. Fig. 10 a and b show SEM micrographs of the FA mortar without WCP and FA mortar with $10 \%$ WCP-1 at 7 days.

Fig. $10 \mathrm{c}$ and $\mathrm{d}$ show the SEM micrographs of the FA mortar without WCP and FA mortar with $10 \%$ WCP-1 at 90 days. C-S-H, plate-like portlandite, and needle-like ettringite can be observed in the SEM micrographs. Also, the microstructure of M-1 is slightly looser than that of M0 , both at 7 and 90 days, which may be due to the larger size of WCP particles than that of FA particles.

\section{CONCLUSIONS}

The feasibility of utilizing WCP in FA mortar was studied. Test results for the fresh and hardened performances of FA mortar as well as hydration products are presented and discussed in this paper. Based on the investigation, the following major conclusions can be drawn: 
1. WCP particles contain sharp corners and irregular edges, which is very different from that of FA particles. Besides, old hydration products from the original mortar remain attached to the surface of the stone particles.
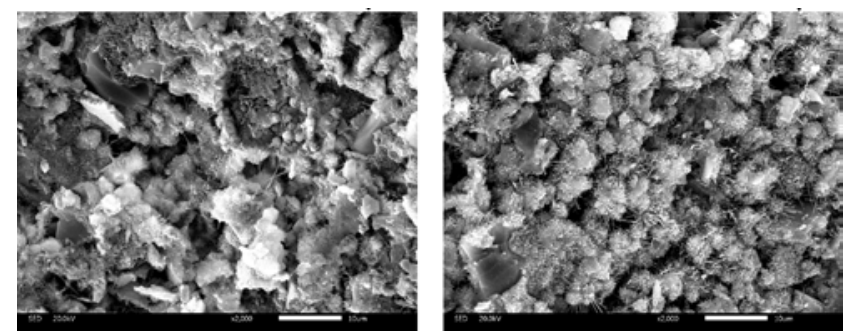

a

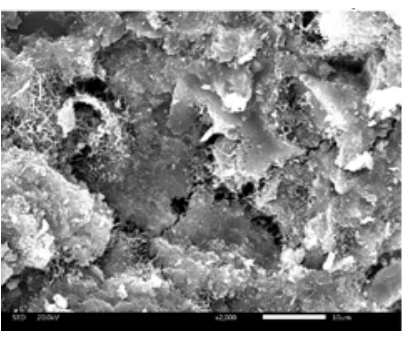

c $-10 \mu \mathrm{m}$
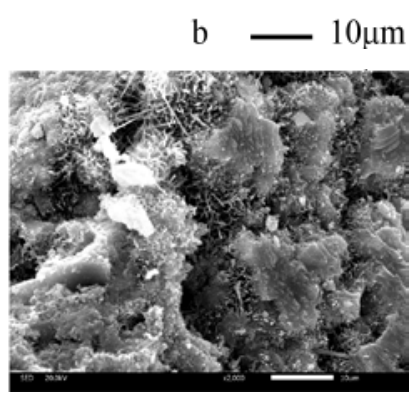

d $-10 \mu \mathrm{m}$
Fig. 10. SEM micrographs of specimens: a-fly ash mortar without WCP-1 at 7 days; $b$ - fly ash mortar with WCP-1 at 7 days; $\mathrm{c}-$ fly ash mortar without WCP-1 at 90 days; $\mathrm{d}$ - fly ash mortar with WCP-1 at 90 days

2. It was demonstrated in this study that WCP could replace up to $10 \% \mathrm{FA}$ in mortar without a significant loss of fresh and hardened performances. Further increased WCP content results in the increasing water requirement but decreasing the flow index, setting time, and strength. The increased water requirement and the reduced flow index can be ascribed to the irregular morphology and rough particle surface of WCP. The decreased setting time is due to the accelerating effect of WCP. The decreased mechanical strength results from the ITZ between the aggregate and the hardened cementitious materials in WCP.

3. The XRD, TG-DTG, and SEM analysis confirm that replacing $10 \%$ FA with WCP did not significantly influence the hydration products and microstructure of mortar. This can be due to the hydration reaction of unhydrated cement grains in WCPs and the accelerating effects of WCP on the hydration of cement.

\section{Acknowledgments}

This research was funded by National Natural Science Foundation of China (grant number 51669004) and Science-Technology Foundation of Guizhou Province (grant number [2017] 5726).

\section{REFERENCES}

1. Rao, A., Jha, K.N., Misra, S. Use of Aggregates from Recycled Construction and Demolition Waste in Concrete Resources Conservation and Recycling 50 (1) 2007: pp. $71-81$. https://doi.org/10.1016/j.resconrec.2006.05.010

2. Zhang, Y.R., Luo, W., Wang, J.J., Wang, Y.F., Xu, Y.Q., Xiao, J.Z. A Review of Life Cycle Assessment of Recycled Aggregate Concrete Construction and Building Materials 209 2019: pp. $115-125$.

https://doi.org/10.1016/j.conbuildmat.2019.03.078

3. Tam, V.W.Y., Soomro, M., Evangelista, A.C.J. A Review of Recycled Aggregate in Concrete Applications (2000-2017) Construction and Building Materials 172 2018: pp. $272-292$. https://doi.org/10.1016/j.conbuildmat.2018.03.240

4. Silva, R.V., de Brito, J., Dhir, R.K. Fresh-State Performance of Recycled Aggregate Concrete: a Review Construction and Building Materials 178 2018: pp. 19-31. https://doi.org/10.1016/j.conbuildmat.2018.05.149

5. Guo, H., Shi, C.J., Guan, X.M., Zhu, J.P., Ding, Y.H., Ling, T.C., Zhang, H.B., Wang, Y.L. Durability of Recycled Aggregate Concrete - a Review Cement and Concrete Composites 89 2018: pp. 251-259. https://doi.org/10.1016/j.cemconcomp.2018.03.008

6. Evangelista, L., de Brito, J. Mechanical Behaviour of Concrete Made with Fine Recycled Concrete Aggregates Cement and Concrete Composites 29 2007: pp. 397-401. https://doi.org/10.1016/j.cemconcomp.2006.12.004

7. Xiao, J.Z., Li, J.B., Zhang, C. Mechanical Properties of Recycled Aggregate Concrete under Uniaxial Loading Cement and Concrete Research 35 (6) 2005: pp. $1187-1194$. https://doi.org/10.1016/j.cemconres.2004.09.020

8. Etxeberria, M., Vazquez, E., $\quad$ Mari, A., $\quad$ Barra, M. Influence of Amount of Recycled Coarse Aggregates and Production Process on Properties of Recycled Aggregate Concrete Cement and Concrete Research 37 (5) 2007: pp. $735-742$.

https://doi.org/10.1016/j.cemconres.2007.02.002

9. Poon, C.S., Shui, Z.H., Lam, L. Effect of Microstructure of ITZ on Compressive Strength of Concrete Prepared with Recycled Aggregates Construction and Building Materials 18 (6) 2004: pp. 461-468. https://doi.org/10.1016/j.conbuildmat.2004.03.005

10. Sagoe-Crentsil, K.K., $\quad$ Brown, T., $\quad$ Taylor, A.H. Performance of Concrete Made with Commercially Produced Coarse Recycled Concrete Aggregate Cement and Concrete Research 31 (5) 2001: pp. 707-712. https://doi.org/10.1016/S0008-8846(00)00476-2

11. Shi, C.J., Li, Y.K., Zhang, J.K., Li, W.G., Chong, L.L., Xie, Z.B. Performance Enhancement of Recycled Concrete Aggregate - a Review Journal of Cleaner Production 112 2016: pp. 466-472. https://doi.org/10.1016/j.jclepro.2015.08.057

12. Ahmari, S., Ren, X., Toufigh, V., Zhang, L.Y. Production of Geopolymeric Binder from Blended Waste Concrete Powder and Fly Ash Construction and Building Materials 35 2012: pp. 718-729. https://doi.org/10.1016/j.conbuildmat.2012.04.044

13. Moon, D.J., Moon, H.Y., Kim, Y.B. Fundamental Properties of Mortar Containing Waste Concrete Powder Geosystem Engineering 8 (4) 2005: pp. 95-100. https://doi.org/10.1080/12269328.2005.10541243

14. Kim, Y.J. Quality Properties of Self-Consolidating Concrete Mixed with Waste Concrete Powder Construction and Building Materials 135 2017: pp. 177-185. https://doi.org/10.1016/j.conbuildmat.2016.12.174 
15. Gastaldi, D., Canonico, F., Capelli, L., $\quad$ Buzzi, L., Boccaleri, E., Irico, S. An Investigation on the Recycling of Hydrated Cement from Concrete Demolition Waste Cement and Concrete Composites 61 2015: pp. 29-35.

https://doi.org/10.1016/j.cemconcomp.2015.04.010

16. Serpell, R., Lopez, M. Reactivated Cementitious Materials from Hydrated Cement Paste Wastes Cement and Concrete Composites 39 2013: pp. 104-114. https://doi.org/10.1016/j.cemconcomp.2013.03.020

17. Shui, Z.H., $\quad$ Xuan, D.X., $\quad$ Wan, H.W., $\quad$ Cao, B.B. Rehydration Reactivity of Recycled Mortar From Concrete Waste Experienced to Thermal Treatment Construction and Building Materials 22 (8) 2008: pp. 1723-1729. https://doi.org/10.1016/j.conbuildmat.2007.05.012

18. Florea, M.V.A., Ning, Z., Brouwers, H.J.H. Activation of Liberated Concrete Fines and Their Application in Mortars Construction and Building Materials 50 2014: pp. 1-12. https://doi.org/10.1016/j.conbuildmat.2013.09.012

19. Liu, Q., $\quad$ Tong, T., $\quad$ Liu, S.H., $\quad$ Yang, D.Z., $\quad$ Yu, Q. Investigation of Using Hybrid Recycled Powder from Demolished Concrete Solids and Clay Bricks as a Pozzolanic Supplement for Cement Construction and Building Materials 73 2014: pp. 754-763. https://doi.org/10.1016/j.conbuildmat.2014.09.066

20. Prosek, Z., $\quad$ Nezerka, V., $\quad$ Hluzek, R., $\quad$ Trejbal, J., Tesarek, P., Karra'a, G. Role of Lime, Fly Ash, and Slag in Cement Pastes Containing Recycled Concrete Fines Construction and Building Materials 201

2019: pp. $702-714$.

https://doi.org/10.1016/j.conbuildmat.2018.12.227

21. Bouaissi, A., $\quad$ Li, L.Y., $\quad$ Moga, L.M., $\quad$ Sandu, I.G., Abdullah, M.M.A., Sandu, A.V. A Review on Fly Ash as a Raw Cementitious Material for Geopolymer Concrete Revista de Chimie-Bucharest 69 (7) 2018: pp. 1661-1667. https://doi.org/10.37358/RC.18.7.6390

22. Wang, J.J., Wang, Y.F., Sun, Y.W., Tingley, D.D., Zhang, Y.R. Life Cycle Sustainability Assessment of Fly Ash Concrete Structures Renewable and Sustainable Energy Reviews 80 2017: pp. 1162-1174. https://doi.org/10.1016/j.rser.2017.05.232

23. Guneyisi, E., Atewi, Y.R., Hasan, M.F. Fresh and Rheological Properties of Glass Fiber Reinforced SelfCompacting Concrete with Nanosilica and Fly Ash Blended Construction and Building Materials 211 2019: pp. 349-362. https://doi.org/10.1016/j.conbuildmat.2019.03.087

24. Hemalatha, T., Ramaswamy, A. A Review on Fly Ash Characteristics - Towards Promoting High Volume Utilization in Developing Sustainable Concrete Journal of Cleaner Production 147 2017: pp. 546-559. https://doi.org/10.1016/j.jclepro.2017.01.114

25. Bouzoubaa, N., Lachemi, M. Self-Compacting Concrete Incorporating High Volumes of Class F Fly Ash Preliminary Results Cement and Concrete Research 31 (3) 2001: pp. 413-420. https://doi.org/10.1016/S0008-8846(00)00504-4

26. Poon, C.S., Lam, L., Wong, Y.L. A Study on High Strength
Concrete Prepared with Large Volumes of Low Calcium Fly Ash Cement and Concrete Research 30 (3) 2000: pp. 447-455. https://doi.org/10.1016/S0008-8846(99)00271-9

27. Siddique, R. Performance Characteristics of High-Volume Class F Fly Ash Concrete Cement and Concrete Research 34 (3) 2004: pp. 487 - 493. https://doi.org/10.1016/j.cemconres.2003.09.002

28. Tam, V.W.Y., Gao, X.F., Tam, C.M. Microstructural Analysis of Recycled Aggregate Concrete Produced from Two-Stage Mixing Approach Cement and Concrete Research 35 (6) 2005: pp. 1195-1203. https://doi.org/10.1016/j.cemconres.2004.10.025

29. Ma, X.W., Wang, Z.Y. Effect of Ground Waste Concrete Powder on Cement Properties Advances in Materials Science and Engineering 2013 2013: pp. 1-5. https://doi.org/10.1155/2013/918294

30. Kim, Y.J., Choi, Y.W. Utilization of Waste Concrete Powder as a Substitution Material for Cement Construction and Building Materials 30 2012: pp. 500-504. https://doi.org/10.1016/j.conbuildmat.2011.11.042

31. Li, J.X., Yang, E.H. Macroscopic and Microstructural Properties of Engineered Cementitious Composites Incorporating Recycled Concrete Fines Cement and Concrete Composites 78 2017: pp. 33-42. https://doi.org/10.1016/j.cemconcomp.2016.12.013

32. Rakhimova, N.R., Rakhimov, R.Z. Hydrated Portland Cement as an Admixture to Alkali-Activated Slag Cement Advances in Cement Research 27 (2) 2015: pp. 107-117. https://doi.org/10.1680/adcr.13.00072

33. Felekoglu, B. Effects of PSD and Surface Morphology of Micro-Aggregates on Admixture Requirement and Mechanical Performance of Micro-Concrete Cement and Concrete Composites 29 (6) 2007: pp. 481-489. https://doi.org/10.1016/j.cemconcomp.2006.12.008

34. Soliman, A.M., Nehdi, M.L. Self-Accelerated Reactive Powder Concrete Using Partially Hydrated Cementitious Materials ACI Materials Journal 108 (6)

2011: pp. 596-604. https://doi.org/10.1002/best.201100062

35. Knudsen, T. Early Hydration of Tricalcium Silicate. I. Kinetics of the Hydration Process and the Stoichiometry of the Hydration Products - Discussion Cement and Concrete Research 9 (6) 1979: pp. 799-800. https://doi.org/10.1016/0008-8846(79)90077-2

36. Boudali, S., $\quad$ Kerdal, D.E., $\quad$ Ayed, K., Abdulsalam, B., Soliman, A.M. Performance of Self-Compacting Concrete Incorporating Recycled Concrete Fines and Aggregate Exposed to Sulphate Attack Construction and Building Materials 124 2016: pp. 705-713. https://doi.org/10.1016/j.conbuildmat.2016.06.058

37. Shaikh, F.U.A., Supit, S.W.M. Mechanical and Durability Properties of High Volume Fly Ash (HVFA) Concrete Containing Calcium Carbonate $\left(\mathrm{CaCO}_{3}\right)$ Nanoparticles Construction and Building Materials 70 2014: pp. 309-321. https://doi.org/10.1016/j.conbuildmat.2014.07.099

(c) Yang et al. 2022 Open Access This article is distributed under the terms of the Creative Commons Attribution 4.0 International License (http://crativecommons.org/licenses/by/4.0/), which permits unrestricted use, distribution, and reproduction in any medium, provided you give appropriate credit to the original author(s) and the source, provide a link to the Creative Commons license, and indicate if changes were made. 